\title{
Correction to: Advancing Home Based Parenting Programs through the Use of Telehealth Technology
}

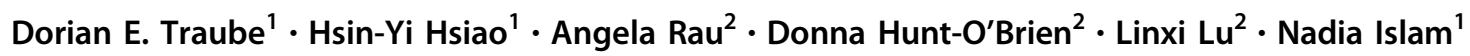

Published online: 4 July 2019

(c) Springer Science+Business Media, LLC, part of Springer Nature 2019

\section{Correction to: Journal of Child and Family Studies} https://doi.org/10.1007/s10826-019-01458-w

The original version of this article unfortunately contained a mistake. The funding information was missing. It should read as follows:
Funding This work was supported by the Coalition for Research on Engagement and Well-Being (CREW) and the Overdeck Family Foundation.

The original article can be found online at https://doi.org/10.1007/ s10826-019-01458-w.

Dorian E. Traube

traube@usc.edu

1 Suzanne Dworak-Peck School of Social Work, University of Southern California, 669W 34th Street, Los Angeles, CA 90089, USA

2 Parents as Teachers National Center, St. Louis, MO, USA 